\title{
Minimally invasive aortic valve replacement with sutureless valve is the appropriate treatment option for high-risk patients and the "real alternative" to transcatheter aortic valve implantation
}

\author{
Mattia Glauber, MD, and Antonio Miceli, MD, $\mathrm{PhD}$
}

\footnotetext{
From the Centro Cardiotoracico, Istituto Clinico Sant'Ambrogio, Gruppo Ospedaliero San Donato, Milan, Italy. Disclosers: M.G. has financial interest in Sorin. The other author has nothing to disclose with regard to commercial support.

Received for publication Oct 7, 2015; accepted for publication Oct 8, 2015; available ahead of print Nov 19, 2015. Address for reprints: Antonio Miceli, MD, $\mathrm{PhD}$, Centro Cardiotoracico Istituto, Clinico Sant'Ambrogio, Gruppo Ospedaliero San Donato, Via Faravelli 16 20149, Milan, Italy (E-mail: antoniomiceli79@alice.it).

J Thorac Cardiovasc Surg 2016;151:610-3

$0022-5223 / \$ 36.00$

Copyright (c) 2016 by The American Association for Thoracic Surgery

http://dx.doi.org/10.1016/j.jtcvs.2015.10.028
}

Aortic valve replacement through a full sternotomy is the conventional approach for the treatment of aortic valve stenosis, and clinical outcomes have significantly improved in the last decade, despite gradual increases in patient age and overall risk profile. ${ }^{1}$ Nevertheless, new alternative treatment options have been introduced into the clinical practice with the aim of reducing the "invasiveness" of the surgical procedure while maintaining the same quality and safety as a conventional approach. ${ }^{2}$ Currently, there are controversies regarding the definition of minimally invasive aortic valve replacement (MIAVR). The Society of Thoracic Surgeons database defines as minimally invasive any procedure not performed with a full sternotomy and cardiopulmonary bypass support and specifically refers to the transcatheter aortic valve implantation (TAVI). ${ }^{3}$ Conversely, a scientific statement of the American Heart Association defines minimally invasive cardiac surgery as a procedure done with a small chest incision that does not include the conventional full sternotomy, distinguishing between the percutaneous and surgical approaches. ${ }^{4}$ We prefer the latter definition, because it highlights the concept that MIAVR is an operation-specific strategy aiming at reducing the surgical invasiveness. $^{2}$

The most common MIAVR approach is the ministernotomy, followed by the right anterior minithoracotomy. Compared with conventional surgery, MIAVR has shown excellent outcomes in terms of mortality, morbidities, and patient satisfaction while providing faster recovery, shorter hospital stay, and better cosmetic results. Several metaanalyses have shown that MIAVR has the advantage of reducing bleeding and blood transfusions, atrial fibrillation, wound infection, and ventilation times, and it improves the respiratory function and reduces the time to return to normal activities. ${ }^{5-9}$ As consequence, MIAVR is associated with fewer rehabilitation resources and reduces costs. These benefits seem to be more evident in patients undergoing right anterior minithoracotomy. ${ }^{10,11}$ Despite

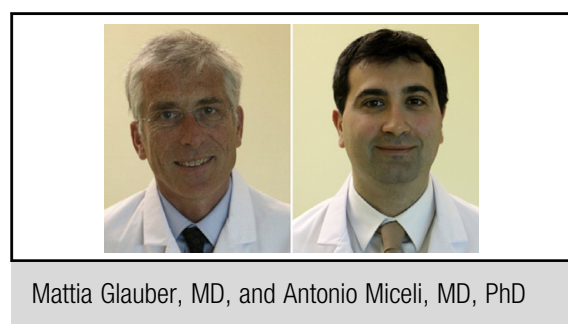

Central Message
Minimally invasive aortic valve replacement
with a sutureless valve is the first-line treatment
option for operable high-risk patients.

See Articles page 735 , page 833 and 841 in the October issue, and page 1570 in the December issue.

See Editorial Commentary page 743.

these results, MIAVR is performed in a minority of heart centers, and traditionalists claim that it is not "surgeon friendly" because it is technically more complex and requires a long learning curve. ${ }^{12,13}$ The reduction in working space for the exposure and implantation of a sutured valve is more challenging and reflects longer operative times associated with this procedure. Prolonged cardiopulmonary bypass and crossclamp times are associated with adverse outcomes, raising some concerns regarding MIAVR's safety in elderly and high-risk patients. $^{14,15}$ In this setting, the drawback of increasing operative times could be avoided by the adoption of sutureless technology, which facilitates the MIAVR approach.

In recent years, 3 different sutureless and rapiddeployment aortic valves have been introduced in Europe as alternatives to conventional biologic sutured valves for the treatment of medium- to high-risk patients undergoing aortic valve replacement. The Perceval S valve (Sorin Biomedica Cardio srl, Salluggia, Italy), Enable valve (Medtronic, Inc, Minneapolis, Minn), and Edwards Intuity valve system (Edwards Lifesciences, Irvine, Calif) have been designed to avoid passing the stitches through the annulus and suture knotting to simplify the surgical procedure and minimize the ischemic time. All these sutureless valves have shown excellent clinical and hemodynamic outcomes, no structural valve deterioration, and high freedom 
from valve reoperation as late as 5 years. ${ }^{16-18} \mathrm{~A}$ recent meta-analysis of more than 1000 high-risk patients with an expected mortality of $10 \%$ reported that overall early and 1 -year mortalities were $2.1 \%$ and $4.9 \%$, respectively, while the 1-year incidences of stroke, valve deterioration. and endocarditis were $1.5 \%, 0.4 \%$, and $2.2 \%$, respectively. Finally, the overall rate of major paravalvular leakage $(>2+)$ was $3 \%$. Only $40 \%$ of patients, however, benefited from a minimally invasive approach. ${ }^{19}$ We have described the largest case series of patients undergoing a minimally invasive approach either through ministernotomy or right anterior minithoracotomy with sutureless valves and reported outstanding results. Operative mortality was $0.7 \%$, and relative to our previous studies with stented valves, we found an overall $40 \%$ reduction in the crossclamp and cardiopulmonary bypass times, suggesting that sutureless valves facilitate the MIAVR approach and standardize the surgical technique. ${ }^{20}$ Finally, the rate of major paravalvular leakage was $1.8 \%$, similar to the Placement of Aortic Transcatheter Valves (PARTNER) 1A trial for stented valves. ${ }^{21}$ The reduction of ischemic time was confirmed in comparative studies between sutureless and conventional stented valves. ${ }^{22-24}$ These results have raised the hypothesis that the MIAVR approach with sutureless valves might be considered an alternative procedure to TAVI for high-risk patients.

TAVI was originally designed to treat a group of patients with severe aortic stenosis who would be at prohibitive risk when undergoing a standard open procedure, and nowadays it is increasingly performed for high-risk patients. Despite the great enthusiasm for this new technology, however, the PARTNER trial failed to show any potential advantage of TAVI relative to the conventional surgery. ${ }^{21}$ Furthermore, several studies and recent meta-analyses of more than 8000 patients have concluded that TAVI is likely ineffective in reducing early and midterm all-cause of mortality versus surgical aortic valve replacement in high-risk patients. ${ }^{25-31}$ Nevertheless, subanalysis of randomized trials has shown TAVI to be associated with higher incidences of neurologic events, vascular complications, pacemaker requirement, and moderate or severe aortic regurgitation. ${ }^{25}$ In this regard, TAVI is a palliative solution that leaves the native valve in situ; this might explain the higher rates of stroke, atrioventricular block, and paravalvular leakage. Conversely, the surgical approach has the advantage of removing the diseased valve and allows an accurate débridement of the calcified aortic annulus, resulting in a lower incidence of postoperative complications, especially in terms of paravalvular leakage. It has been shown that paravalvular leakage is a predictor of poor survival and should be avoided. ${ }^{32}$ The main limitation of these studies is that the surgical outcomes are related to conventional surgery, consisting of full sternotomy and sutured aortic prosthetic valves. To date, there have been only 2 studies that rely on MIAVR and sutureless technology. In a propensitymatched analysis, Santarpino and colleagues ${ }^{33}$ have shown better outcomes in patients undergoing ministernotomy and sutureless aortic valve replacement than in those treated with a TAVI approach, suggesting that this combination of these new technologies may be considered the first-line treatment for high-risk patients considered in the gray zone between TAVI and conventional surgery. Our group reported similar results when outcomes were compared between the right anterior minithoracotomy approach with sutureless and TAVI procedures. ${ }^{34}$ Interestingly, Jahangiri and coworkers ${ }^{35}$ found that $42 \%$ of patients referred for TAVI underwent conventional surgery and did well. This finding supports our hypothesis that a minimally invasive approach associated with a sutureless valve would be the real treatment option for high-risk patients considered to be operative candidates.

Finally, an analysis of cost-effectiveness of these procedures should be considered. A cost-utility analysis of TAVI concluded that it is not recommended to reimburse TAVI for high-risk patients who are operative candidates, because these patients had no survival benefit after 1 year with TAVI, their risk of stroke was double, and their costs were higher. ${ }^{36}$ In addition, a systematic review and a large Society of Thoracic Surgeons study concluded that TAVI is a potentially cost-effective alternative to medical therapy for patients not considered to be operative candidates; however, it is not the most cost-effective strategy for medium- and high-risk patients who are operative candidates, because evidence is currently insufficient to justify economically the use of TAVI in preference to conventional surgery. ${ }^{37,38}$ These studies focus on patients undergoing conventional surgery; no study has yet focused on the cost-utility of MIAVR with sutureless technology.

In light of these considerations, we strongly believe that the presence of a heart team is mandatory for the treatment of high-risk patients undergoing aortic valve replacement. Although we recommend a TAVI procedure for patients who are not candidates for a surgical procedure, a tailored approach should be considered for highrisk patients considered to be operative candidates, taking into account the patient's morbidities, the frailty conditions, and the life expectancy. In this setting, a minimally invasive approach with a sutureless valve might be considered a treatment option for high-risk patients and the "real alternative" to a TAVI procedure. A welldesigned randomized trial, however, is required to confirm our hypothesis. 


\section{References}

1. Brown JM, O'Brien SM, Wu C, Sikora JA, Griffith BP, Gammie JS. Isolated aortic valve replacement in North America comprising 108,687 patients in 10 years: changes in risks, valve types, and outcomes in the Society of Thoracic Surgeons National Database. J Thoracic Cardiovasc Surg. 2009; 137:82-90.

2. Schmitto JD, Mokashi SA, Cohn LH. Minimally invasive valve surgery. J Am Coll Cardiol. 2010;56:455-62.

3. Society of Thoracic Surgeons National Database spring 2003: executive summary. Durham, NC: Duke Clinical Research Institute; 2003.

4. Rosengart TK, Feldman T, Borger MA, Vassiliades TA Jr, Gillinov M, Hoercher KJ, et al; American Heart Association Council on Cardiovascular Surgery and Anesthesia; American Heart Association Council on Clinical Cardiology; Functional Genomics and Translational Biology Interdisciplinary Working Group; Quality of Care and Outcomes Research Interdisciplinary Working Group. Percutaneous and minimally invasive valve procedure: a scientific statement from the American Heart Association Council on Cardiovascular Surgery and Anesthesia, Council on Clinical Cardiology, Functional Genomics and Translational Biology Interdisciplinary Working Group, and Quality of Care and Outcomes Research Interdisciplinary Working Group. Circulation. 2008; 117:1750-67.

5. Brown ML, McKellar SH, Sundt TM, Schaff HV. Ministernotomy versus conventional sternotomy for aortic valve replacement: a systematic review and meta-analysis. J Thorac Cardiovasc Surg. 2009;137: 670-9.e5.

6. Murtuza B, Pepper JR, Stanbridge RD, Jones C, Rao C, Darzi A, et al. Minimal access aortic valve replacement: is it worth it? Ann Thorac Surg. 2008;85: 1121-31.

7. Gilmanov D, Bevilacqua S, Murzi M, Cerillo AG, Gasbarri T, Kallushi E, et al. Minimally invasive and conventional aortic valve replacement: a propensity score analysis. Ann Thorac Surg. 2013;96:873-943.

8. Glauber M, Miceli A, Bevilacqua S, Farneti PA. Minimally invasive aortic valve replacement via right anterior minithoracotomy: early outcomes and midterm follow-up. J Thorac Cardiovasc Surg. 2011;142:1577-9.

9. Glauber M, Gilmanov D, Farneti PA, Kallushi E, Miceli A, Chiaramonti F, et al. Right anterior minithoracotomy for aortic valve replacement: 10-year experience of a single center. J Thorac Cardiovasc Surg. 2015;150: 548-56.e2.

10. Glauber M, Miceli A, Gilmanov D, Ferrarini M, Bevilacqua S, Farneti PA, et al. Right anterior minithoracotomy versus conventional aortic valve replacement: a propensity score matched study. J Thoracic Cardiovasc Surg. 2013; 145:1222-6.

11. Miceli A, Murzi M, Gilmanov D, Fugà R, Ferrarini M, Solinas M, et al. Minimally invasive aortic valve replacement using right minithoracotomy is associated with better outcomes than ministernotomy. J Thoracic Cardiovasc Surg. 2014;148:133-7.

12. Cooley DA. Minimally invasive valve surgery versus the conventional approach. Ann Thorac Surg. 1998;66:1101-5.

13. Foghsgaard S, Schmidt TA, Kjaergard HK. Minimally invasive aortic valve replacement: late conversion to full sternotomy doubles operative times. Tex Heart Inst J. 2009;36:293-7.

14. Al Sarraf N, Thalib L, Hughes A, Houlihan M, Tolan M, Young V, et al. Crossclamp time is an independent predictor of mortality and morbidity in low- and high-risk cardiac patients. Int J Surg. 2011;9:104-9.

15. Ranucci M, Frigiola A, Menicanti L, Castelvecchio S, de Vincentiis C, Pistuddi V. Aortic cross-clamp time, new prostheses and outcomes, in aortic valve replacement. J Heart Valve Dis. 2012;21:732-9.

16. Englberg L, Carrel TP, Doss M, Sadowski J, Bartus K, Eckstein FF, et al. Clinical performance of a sutureless aortic bioprosthesis: five-year results of the 3 f Enable long term follow-up study. J Thorac Cardiovasc Surg. 2014; 148:1681-7.

17. Shrestha M, Fischlein T, Meuris B, Flameng W, Carrel T, Madonna F, et al. European multicentre experience with the sutureless Perceval valve: clinical and haemodynamic outcomes up to 5 years in over 700 patients. Eur J Cardiothorac Surg. March 6, 2015 [Epub ahead of print].

18. Haverich A, Wahlers TC, Borger MA, Shrestha M, Kocher AA, Walther T, et al. Three-year hemodynamic performance, left ventricular mass regression, and prosthetic-patient mismatch after rapid deployment aortic valve replacement in 287 patients. J Thorac Cardiovasc Surg. 2014;148: 2854-60.
19. Phan K, Tsai Y, Niranjan N, Bouchard D, Carrel TP, Dapunt OE, et al. Sutureless aortic valve replacement: a systematic review and meta-analysis. Ann Cardiothorac Surg. 2015;4:100-11.

20. Miceli A, Santarpino G, Pfeiffer S, Murzi M, Gilmanov D, Concistré G, et al. Minimally invasive aortic valve replacement with Perceval S sutureless valve: early outcomes and one-year survival from two European centers. J Thoracic Cardiovasc Surg. 2014;148:2838-43.

21. Svensson LG, Tuzcu M, Kapadia S, Blackstone EH, Roselli EE, Gillinov MA, et al. A comprehensive review of the PARTNER trial. J Thorac Cardiovasc Surg. 2013;145(3 Suppl):S11-6.

22. Gilmanov D, Miceli A, Ferrarini M, Farneti PA, Murzi M, Solinas M, et al. Aortic valve replacement through right anterior minithoracotomy: can sutureless technology improve clinical outcomes? Ann Thorac Surg. 2014;98:1585-92.

23. Borger MA, Moustafine V, Conradi L, Knosalla C, Richter M, Merk DR, et al. A randomized multicenter trial of minimally invasive rapid deployment versus conventional full sternotomy aortic valve replacement. Ann Thorac Surg. 2015;99: $17-25$.

24. Gilmanov D, Miceli A, Bevilacqua S, Farneti P, Solinas M, Ferrarini M, et al. Sutureless implantation of the Perceval S aortic valve prosthesis through right anterior minithoracotomy. Ann Thorac Surg. 2013;96:2101-8.

25. Cao C, Ang SC, Indraratna P, Manganas C, Bannon P, Black D, et al. Systematic review and meta-analysis of transcatheter aortic valve implantation versus surgical aortic valve replacement for severe aortic stenosis. Ann Cardiothorac Surg. 2013;2:10-23.

26. Panchal HB, Ladia V, Desai S, Shah T, Ramu V. A meta-analysis of mortality and major adverse cardiovascular and cerebrovascular events following transcatheter aortic valve implantation versus surgical aortic valve replacement for severe aortic stenosis. Am J Cardiol. 2013;112:850-60.

27. Takagi H, Niwa M, Mizuno Y, Goto S, Umemoto T, All-Literature Investigation of Cardiovascular Evidence (ALICE) Group. A meta-analysis of transcatheter aortic valve implantation versus surgical aortic valve replacement. Ann Thorac Surg. 2013;96:513-9.

28. Jilaihawi H, Chakravarty T, Weiss RE, Fontana GP, Forrester J, Makkar RR. Meta-analysis of complications in aortic valve replacement: comparison of Medtronic-Corevalve, Edwards-Sapien and surgical aortic valve replacement in 8,536 patients. Catheter Cardiovasc Interv. 2012;80:128-38.

29. Conradi L, Seiffert M, Treede H, Silaschi M, Baldus S, Schirmer J, et al. Transcatheter aortic valve implantation versus surgical aortic valve replacement: a propensity score analysis in patients at high surgical risk. J Thoracic Cardiovasc Surg. 2012;143:64-71.

30. D’Onofrio A, Rizzoli G, Messina A, Alfieri O, Lorusso R, Salizzoni S, et al. Conventional surgery, sutureless valves, and transapical aortic valve replacement: what is the best option for patients with aortic valve stenosis? A multicenter, propensity-matched analysis. J Thorac Cardiovasc Surg. 2013;146:1065-70; discussion 1070-1.

31. Muneretto C, Alfieri O, Cesana BM, Bisleri G, De Bonis M, Di Bartolomeo R, et al. A comparison of conventional surgery, transcatheter aortic valve replacement, and sutureless valves in "real-word" patients with aortic stenosis and intermediate- to high-risk profile. J Thoracic Cardiovasc Surg. 2015;150: 1570-9.

32. Mack MJ, Leon MB, Smith CR, Miller CD, Moses JW, Tuzcu EM, et al; PARTNER 1 trial investigators. 5-year outcomes of transcatheter aortic valve replacement or surgical aortic valve replacement for high surgical risk patients with aortic stenosis (PARTNER 1): a randomised controlled trial. Lancet. 2015;383: 2477-84.

33. Santarpino G, Pfeiffer S, Jessl J, Dell'Aquila AM, Pollari F, Pauschinger M, et al. Sutureless replacement versus transcatheter valve implantation in aortic valve stenosis: a propensity-matched analysis of 2 strategies in high-risk patients. $J$ Thorac Cardiovasc Surg. 2014;147:561-7.

34. Miceli A, Gilmanov D, Murzi M, Marchi F, Ferrarini M, Cerillo AG, et al. Minimally invasive aortic valve replacement with a sutureless valve through a right anterior mini-thoracotomy versus transcatheter aortic valve implantation in high-risk patients. Eur J Cardiothorac Surg. June 25, 2015 [Epub ahead of print].

35. Jahangiri M, Laborde JC, Roy D, Williams F, Abdulkareem N, Brecker S. Outcome of patients with aortic stenosis referred to a multidisciplinary meeting for transcatheter valve. Ann Thorac Surg. 2011;91:411-5.

36. Neyt M, Van Brabandt H, Devriese S, Van De Sande S. A cost-utility analysis of transcatheter aortic valve implantation in Belgium: focusing on a well-defined and identifiable population. BMJ Open. 2012;2:e01032. 
37. Indraratna $\mathrm{P}$, Ang SC, Gada H, Yan TD, Manganas C, Bannon P, et al. Systematic review of the cost-effectiveness of transcatheter aortic valve implantation. $J$ Thoracic Cardiovasc Surg. 2014;148:509-14.
38. Ailawadi G, LaPar DJ, Speir AM, Ghanta RK, Yarboro LT, Crosby IK, et al. Contemporary costs associated with transcatheter aortic valve replacement: a propensity-matched cost analysis. Ann Thorac Surg. 2015. In press.

Access to The Journal of Thoracic and Cardiovascular Surgery Online is reserved for print subscribers!

Full-text access to The Journal of Thoracic and Cardiovascular Surgery Online is available for all print subscribers. To activate your individual online subscription, please visit The Journal of Thoracic and Cardiovascular Surgery Online, point your browser to http://www.mosby.com/jtcvs, follow the prompts to activate your online access, and follow the instructions. To activate your account, you will need your subscriber account number, which you can find on your mailing label (note: the number of digits in your subscriber account number varies from 6 to 10). See the example below in which the subscriber account number has been circled:

\section{Sample mailing label}

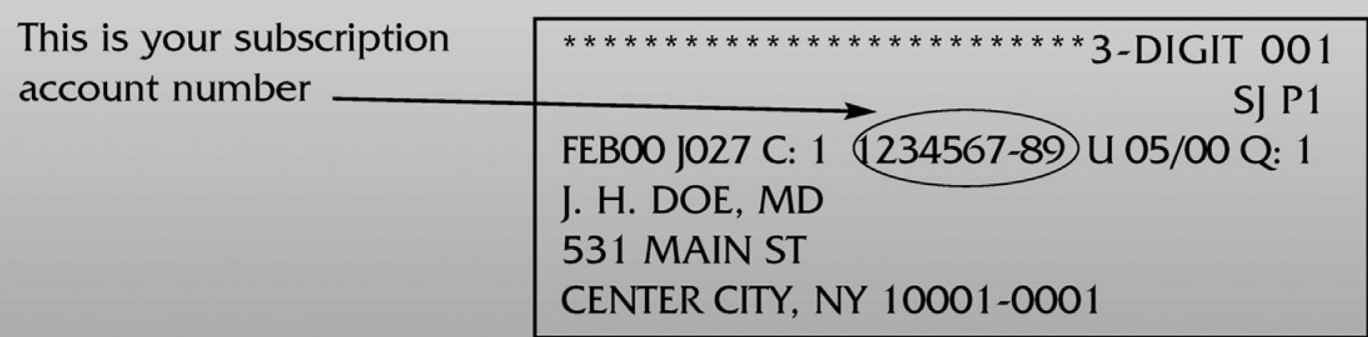

Personal subscriptions to The Journal of Thoracic and Cardiovascular Surgery Online are for individual use only and may not be transferred. Use of The Journal of Thoracic and Cardiovascular Surgery Online is subject to agreement to the terms and conditions as indicated online. 